Introduction Stress related symptoms are common in staff of large tertiary hospitals. However, the quality of support received from management varies widely. As a Specialist Registrar in the Occupational Health Department of such a hospital, I sought to improve the competency of line managers across four key areas of stress management by providing an educational intervention.

Methods Using a standardised self-assessment rating scale, a learning and development need was identified among line managers. This information was used in order to prepare a workshop, using a standardised approach, aimed at improving their understanding of stress, how to recognise stress in the workplace and how to manage an employee experiencing stress. After delivering the workshop, participants subsequently repeated the self-assessment rating scale, and the change in competency was measured.

Results A statistically significant improvement was seen across all four competency levels measured, with p-values for each measuring less than 0.05 . The mean scores from all participants in their post-intervention self-assessments were in excess of the $90 \%$ threshold for effectiveness in each area.

Discussion Feedback following the workshop was positive and a clear improvement in managers' competency was achieved. This was further supported by examining referrals to the department from workshop participants both before and after the intervention, with an improvement in the quality of information supplied noted.

Although the number of participants was small, with seven participants fully completing all evaluations, each participant is responsible for an average of twenty employees'. Therefore the intervention has the potential to positively affect up to 150 employees, with a consequent reduction in absenteeism, and healthcare costs attributable to stress, likely. In order to accurately quantify this, long-term absenteeism rates should be measured.

The findings of this project demonstrate a clear benefit in engaging managers in educational workshops to improve their competency in dealing with employees who are experiencing work-related stress.

\section{FACING COMPLAINING CUSTOMER AND SUPPRESSED EMOTION AT WORKSITE RELATED TO SLEEP DISTURBANCE IN KOREA}

\begin{abstract}
1,2Sung-Shil Lim*, 1,2,3,4 Jin-Ha Yoon, 1,2,3,4 Jong-Uk Won, 1,2,3,4 Jaehoon Roh. 'Graduate School of Public Health, Yonsei University, South Korea, Seoul; ${ }^{2}$ The Institute for Occupational Health, Yonsei University College of Medicine, South Korea, Seoul; ${ }^{3}$ Incheon Workers' Health Centre, South Korea, Incheon; ${ }^{4}$ Department of Preventive Medicine and Public Health, Yonsei University College of Medicine, South Korea, Seoul
\end{abstract}

\subsection{6/oemed-2018-ICOHabstracts.1715}

Introduction In recent years, there has been increasing interest in emotional labour because of the shift of the economy from the manufacturing to the service sector. This work involves a great deal of so-called 'emotional labour'. Sleep disturbance represents an enormous impact on the wellbeing of individuals and society as a whole. This study aimed to investigate the effect of facing complaining customer and suppressed emotion at worksite on sleep disturbance among working population.

Methods We assumed that (1) engaging complaining customers and (2) suppressing emotions at a worksite would be crucial factors in potential excessive emotional demand in service workers. This study set out to assess the association between sleep disturbance and emotional demands, including the influence of 1) and 2) above in a population-based study from a nationally representative sample of Korean workers, the Korean Working Condition Survey (KWCS) which has comprehensive questionnaires regarding the occupational information for almost fifty thousand workers in Korea. Statistical analysis was performed using the SAS 9.2 software (SAS Institute Inc., Cary, NC, USA.).

Results Among workers in working environments where they always engage complaining customers had a significantly higher risk for sleep disturbance than rarely group (The OR $[95 \% \mathrm{CI}] ; 5.46[3.43-8.68]$ in male, $5.59[3.30-9.46]$ in female workers). The OR $(95 \% \mathrm{CI})$ for sleep disturbance was $1.78(1.16-2.73)$ and $1.63(1.02-2.63)$, for the male and female groups always suppressing their emotions at the workplace compared with those rarely group. Compared to those who both rarely engaged complaining customers and rarely suppressed their emotions at work, the OR (CI) for sleep disturbance was $9.66(4.34-20.80)$ and 10.17 (4.46-22.07), for men and women always exposed to both factors.

Conclusion The level of emotional demand, including engaging complaining customers and suppressing emotions at the workplace is significantly associated with sleep disturbance among Korean working population.

\section{PRECARIOUS EMPLOYMENT CONDITIONS AND ITS ASSOCIATION WITH HEART RATE VARIABILITYIN MEXICAN HOSPITAL WORKERS}

${ }^{1} G$ Martínez*, ${ }^{2} \mathrm{~K}$ Radon, ${ }^{2} \mathrm{D}$ Rodriguez, ${ }^{2} \mathrm{R}$ Herrera, ${ }^{2} \mathrm{M}$ Parra. ${ }^{1}$ South Central Hospital of High Specialty of Petroleos Mexicanos; ${ }^{2} \mathrm{CIH}$ Institute for Occupational, Social and Environmental Medicine, University Hospital Munich (LMU), Germany

\subsection{6/oemed-2018-ICOHabstracts. 1716}

Introduction Psychosocial working conditions such as employment precariousness or an imbalance between effort and reward at the workplace might result in cardiovascular diseases. One marker of cardiovascular effects is Heart Rate Variability (HRV). The objective of this study was to analyse the relation between precarious employment and HRV in health and administrative workers employed at a hospital in Mexico City.

Methods In this cross-sectional study, 206 hospital employees without known cardiovascular diseases participated (response 90\%). An interview-based questionnaire assessed sociodemographics, employment conditions, employment precariousness (EPRES) and lifestyle factors. HRV was measured over $10 \mathrm{~min}$ in sitting posture. Standard Deviation (SDNN) of the RR intervals over a five minutes was calculated (IBM SPSS 24).

Results Healthcare personnel $(n=106)$ was less likely to be active smokers (9\% vs 29\%) than administrative workers. Healthcare workers reported lower employment duration ( $24 \%$ vs $7 \%$ duration $<5$ years), working more hours per week ( $19 \%$ vs $7 \%$ working $\geq 60$ hours/week), and more shift work (22\% vs $11 \%)$ than the comparison group. They were more affected by temporality of the contract ( $27 \%$ vs $7 \%)$ and were less likely to suffer from economic deprivation (46\% vs 69\%; all $\left.\mathrm{p}_{\mathrm{Chi}}{ }^{2}<0.05\right)$ than office workers. Mean SDNN did not differ between healthcare workers $(49,93 \pm$ SD $31,91)$ and administrative workers $\left(54,26 \pm 41,50\right.$; $\mathrm{p}_{\mathrm{t}}$ Test $=0,33)$. This was confirmed after adjusting for potential confounders. The only significant work-related predictor of 
SDNN was shift work (Beta: $-16,68 ; 95 \%$ CI: $-30,69$ to $-2,67)$.

Discussion Although Mexican healthcare professionals frequently suffer from precarious employment conditions, shift work was the main predictor for lower HRV in our study population.

\section{WORKER'S SUPPORT PROGRAM FOR URBAN VIOLENCE IN A BRAZILIAN LOGISTICS COMPANY}

${ }^{1}$ VL Zaher-Rutherford*, ${ }^{2}$ V Farias, ${ }^{2}$ FG Martins Filho. ${ }^{1}$ Faculty of Medicine, University of São Paulo, São Paulo, Brazil; ${ }^{2}$ Occupational Physician in a Logistics Company, São Paulo, Brazil

\subsection{6/oemed-2018-ICOHabstracts. 1717}

Introduction Violence in a developing country can be very common and particularly increases in an economic downturn. In a logistics company employing hundreds of drivers who sometimes face urban violence, this problem can be a great challenge for the occupational health as well as the security teams.

Methods A program to assist workers in dealing with violent incidents they encounter while working was developed in 2008. This program was developed to address legal, security, psychological, and occupational health requirements of these workers. The psychological support aspects of the program are accomplished by phone within 24 to 48 hours after the incident, with follow-ups after 15 and 30 day period.

Results Workers involved in violent incidents are provided with a company attorney when reporting the incident to the police. They also receive a phone call from a psychologist. The psychologist provides support, listening to the workers description of the incident, administering a psychological assessment, and then referring the worker for further therapy or to a psychiatrist when appropriate. Commonly, such incidents do not have physical ramifications for the worker but instead often have psychological consequences that are more difficult to measure. The same worker can experience several such assaults. Psychological issues can manifest with just one event, but there are some workers who have been involved in dozens of these events.

Discussion This support program for workers is important and necessary to help them to cope with violent incidents even when considering the ideal solution of preventing such incidents from occurring in the first place. The challenge for occupational health professionals is how to mitigate the consequences for the involved workers who are otherwise subject to potentially severe psychological and physical injuries. This program helps by opening a new communications channel and support avenue to assist the company in addressing such complex and delicate situations.

\section{LONGITUDINAL PSYCHOLOGICAL SUPPORT AFTER OCCUPATIONAL VIOLENCE IN A BRAZILIAN LOGISTICS COMPANY}

'LG Lopes, 'C Tech, 'LR Andrade, 'S Silva, 'SGB Moreira, 'V Farias, 'FG Martins Filho, 2J Silva Jr, 3,4V Zaher-Rutherford. 'Occupational Physician in a Logistics Company, São Paulo, Brazil; ${ }^{2}$ National Social Security Institute, São Paulo, Brazil; ${ }^{3}$ Agregar Consulting Practice and the; ${ }^{4}$ Faculty of Medicine, University of São Paulo, São Paulo, Brazil

\subsection{6/oemed-2018-ICOHabstracts. 1718}

Introduction Violence at work is a psychosocial risk that safety and health occupational teams have to deal with nowadays. A program to assist workers in dealing with violent incidents was developed in 2008 in a national logistics company to address legal, security, psychological, and occupational health requirements for workers. The psychological support aspects of the program are accomplished by phone within 24 to 48 hours after the incident, with follow-ups after 15 and 30 day periods. The objective of this study was to gather data relating to psychological support requirements of workers who had been victims of violent episodes in the course of their work, typically during the theft of their cargo.

Methods A longitudinal study carried out in a logistics company located in São Paulo, Brazil, during 2014-2016. Data was gathered from company notifications of violent incidents relating to theft of cargo in 5 regions of the country.

Results The average number of violent events during the three years of the study did not vary significantly from year to year and averaged 1833 events per year. The greatest frequency of events occurred during the second half of the year $(53.9 \%$ average). The regions of the country with the highest percentage of events were the southeast $(68.3 \%$ average $)$ and the least was the north $(2.3 \%$ average $)$. Requests for psychological support rose by an average of $69.0 \%$ during the study period. About $16.0 \%$ of events resulted in support requests in 2013, while $43.6 \%$ of cases generated support requests in 2016. The region generating the most psychological support requests was the southeast $(33.0 \%$ average $)$ and the least was the northeast (22.7\% average).

Discussion The data demonstrated that while the overall number of incidents remained consistent, the number of support requests from workers rose significantly during the study period. We infer from this data that the support program is viewed by the workers as being an effective tool to deal with violent incidents. It is necessary to discuss regional strategies to help increase worker use of the program. It is also recommended to analyse the impacts of violent episodes on workers and whether the psychological follow up reduces the damage to their mental and physical health.

\section{ERGONOMIC ANALYSIS OF ELECTRONIC SPORTS PLAYERS - UNRAVELLING RISKS - POST-GRADUATION IN ERGONOMICS}

${ }^{1} \mathrm{TA}$ Oliveira, ${ }^{2} \mathrm{P}$ Costa, ${ }^{3} \mathrm{HM}$ de Araújo, ${ }^{4} \mathrm{CM}$ de Toledo, ${ }^{2} \mathrm{GF}$ Primo. ${ }^{1}$ Labor Doctor, Postgraduation In Ergonomics At Senac Ribeirão Preto,Americana, Brazil; ${ }^{2}$ Physiotherapist, Postgraduation In Ergonomics At Senac Ribeirão Preto, Piracicaba, Brazil; ${ }^{3}$ Architect, Postgraduation In Ergonomics At Senac Ribeirão Preto, Ribeirão Preto, Brazil; ${ }^{4}$ Physical Education teacher, Post-graduation In Ergonomics At Senac Ribeirão Preto, Ribeirão Preto, Brazil

\subsection{6/oemed-2018-ICOHabstracts. 1719}

Introduction Performed Ergonomic Analysis of Work (AET) with professional players of Electronic Sports (mode: League of Legends). It is known through social networks, interactive newspapers and television broadcasters that the modality is on the rise and that it also brings some evidence and difficulties related to pain in the wrists of athletes.

The pains in the fist are in the area of Physical Ergonomics, but can not be considered the origin of the cause. We also know that the work tool of the players is the computer, so the second point to be studied is in the field of Cognitive Ergonomics, where we approach topics related to decision making, memory, reasoning, perception, human-machine interaction, reflexes.Ergonomics has its three established pillars: Physical, Organisational and Cognitive 